\title{
MICROWAVE-ASSISTED SYNTHESIS AND SPECTROSCOPIC PROPERTIES OF NOVEL PYRIDINE-BASED FLUORESCENT MOLECULAR PROBES
}

\author{
P. Fiedor ${ }^{1}$, J. Ortyl ${ }^{1,2}$, M. Galek ${ }^{2}$ \\ ${ }^{1}$ University of Technology in Cracow, Warszawska 24, 31-155 Cracow, Poland \\ ${ }^{2}$ Photo HiTech, Bobrzyńskiego 14, 30-348 Cracow, Poland \\ pfiedor@chemia.pk.edu.pl
}

Keywords: microwave chemistry, synthesis, spectroscopy, fluorophores, molecular probes

\section{Introduction:}

Fluorescent molecular probes become interesting analytical tools in determination and labeling of chemical compounds, and physical properties such as viscosity and polarity. Currently known fluorescent molecular probes can selectively and regardless of the environment detect only few molecules. Their applicability for determination of microviscosity and micro-polarity is limited to narrow range and specific condition. Therefore design and synthesis of novel molecular probes with extended range of operation are highly needed [1].

Derivatives of 2-amino-4,6-diphenyl-pyridine-3-carbonitrile can find application in different fields of science. Depending on the structure of this fluorophore, those compounds exhibit high sensitivity to changes in polarity and viscosity of environment, also concentration of specific cations, and $\mathrm{pH}$ can be determined by measuring of fluorescence spectrum of 2-amino-4,6-diphenyl-pyridine-3-carbonitriles [2]. Knowing that spectroscopic parameters strongly depends on substituents present at phenyl rings of those compounds it is important to examine this influence by synthesis and direct research on synthesized compounds [2]. To enable such studies, cheap, quick and efficient method of synthesis of 2amino-4,6-diphenyl-pyridine-3-carbonitrile derivatives must be used. Variety of synthesis paths for this group of compounds has been proposed at literature, most of them base on two steps reaction $[3,4,5]$. At first step simple Knovenagel condensation of benzaldehyde with malonodinitrile was conducted at methanol solution with catalytic addition of sodium hydroxide. Second step is conducted at high temperature in toluene for $4 \mathrm{~h}$. This traditional way takes long time and consume unnecessary amounts of solvents and substrates [5]. Some solutions of this problems was reported according to literature. Different heterogenic catalytic systems were proposed to solve problem of wasting solvents and materials. Main problem of this approach is that, proposed catalysts are expensive and are hard to reach or obtain [6].

In case employing microwave heating, single step reaction can be performed without or with trace amount of solvent. This approach simplify the procedure of preparation of many derivatives of 2-amino-3-cyanopyridines. Such synthesis strategy was reported, but only very little of derivatives were proven to form at such conditions. The advantage of this method is that, crystalline product was formed after reaction, and after recrystallization from ethanol or 2-propanol pure compounds were obtained $[1,7]$. 


\section{Results and Discussion:}

Traditionally synthesis of 2-amino-4,6-diphenyl-pyridine-3-carbonitriles was divided into two steps. First stage was Knoevenagel condensation between malonodinitrile and proper derivative of benzaldehyde at methanol solution in presence of catalytic amount of sodium hydroxide [5]. Condensation was conducted for $30 \mathrm{~min}$ at room temperature. After that time product was filtrated and washed with cold methanol. Yield of this stage for all investigated structures were higher than $90 \%$.

Second step was a reaction between obtained alikilidene malonodinitirile (1 eq) with proper derivative of acetophenone (1 eq) in presence of ammonium acetate (1.1 eq). Reaction was conducted in toluene (10 eq) at $100^{\circ} \mathrm{C}$ for $4 \mathrm{~h}$ [5]. Reaction path and conditions are presented on scheme 1. After second step of the reaction some impurities were present on TLC, due to that condition, purification on column chromatography was necessary.<smiles>[R]c1ccc(C=O)cc1</smiles>

1<smiles>[R]c1ccc(C=C(C#N)C#N)cc1</smiles>

3<smiles>N#CCC#N</smiles>

2

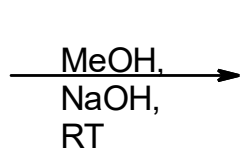
RT

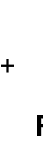<smiles>[R2]c1ccc(C(C)=O)cc1</smiles>

4<smiles>[R]c1ccc(C=C(C#N)C#N)cc1</smiles>

3<smiles>[R]c1ccc(-c2cc(-c3ccc([R])cc3)c(C#N)c(N)n2)cc1</smiles>

\section{$\mathbf{R}_{1}, \mathbf{R}_{2}=\mathrm{CN}, \mathrm{OCH}_{3}, \mathrm{SCH}_{3}$}

PhMe, $\mathrm{NH}_{4} \mathrm{OAc}$, $100^{\circ} \mathrm{C}, 4 \mathrm{~h}$

Scheme 1. Reacon route for traditional synthesis of 2-amino-4,6-diphenyl-pyridine-3carbonitrile derivatives.

Yield of synthesis for derivatives of 2-amino-4,6-diphenyl-pyridine-3-carbonitriles obtained on traditional path are presented in the table 1.

Table 1. Yield of synthesis of 2-amino-4,6-diphenyl-pyridine3-carbonitrile conducted at traditional path.

\begin{tabular}{cccc}
\hline Product & $\mathbf{R}_{\mathbf{1}}$ & $\mathbf{R}_{\mathbf{2}}$ & Yield in traditional synthesis \\
\hline $\mathbf{P 0}$ & $\mathrm{H}$ & $\mathrm{H}$ & $30 \%$ \\
\hline $\mathbf{P 1}$ & $\mathrm{CN}$ & $\mathrm{H}$ & $14 \%$ \\
\hline $\mathbf{P 2}$ & $\mathrm{CN}$ & $\mathrm{OCH}_{3}$ & $30 \%$ \\
\hline $\mathbf{P 3}$ & $\mathrm{CN}$ & $\mathrm{SCH}_{3}$ & $33 \%$ \\
\hline $\mathbf{R} 1$ & $\mathrm{H}$ & $\mathrm{CN}$ & $24 \%$ \\
\hline $\mathbf{R 2}$ & $\mathrm{OCH}_{3}$ & $\mathrm{CN}$ & $15 \%$ \\
\hline $\mathbf{R 3}$ & $\mathrm{SCH}_{3}$ & $\mathrm{CN}$ & $23 \%$ \\
\hline $\mathbf{S 1}$ & $\mathrm{OCH}_{3}$ & $\mathrm{SCH}_{3}$ & $55 \%$ \\
\hline $\mathbf{S 2}$ & $\mathrm{SCH}_{3}$ & $\mathrm{OCH}_{3}$ & $80 \%$ \\
\hline
\end{tabular}


General procedure for microwave synthesis was single step reaction between malonodinitrile (1 eq), and proper derivatives of acetophenone (1 eq), benzaldehyde ( 1 eq) with addition of ammonium acetate (1.1 eq). Reactions were conducted into small amount of toluene (3 eq). To investigate influence of phase transfer catalyst presence in reaction mixture TBAB was added in quantity of 0.04 eq. Reactions were carried out in a Alasca MWD2925GC domestic microwave oven operating at $2450 \mathrm{MHz}$ at a maximum power of $800 \mathrm{~W}$. Time of reaction was selected by studies of reaction progress via TLC to be $210 \mathrm{~s}$. Microwave synthesis path and conditions are presented on scheme 2. After reaction, when resulting mixture was cooled down, product crystalized directly from reaction mixture, in most cases there were no additional impurities visible on TLC. After filtration, washing with cold toluene and recrystallization from methanol products were pure for further investigation.<smiles>[R]c1ccc(C=[OH+])cc1</smiles><smiles>[R]c1ccc(C(C)=O)cc1</smiles>
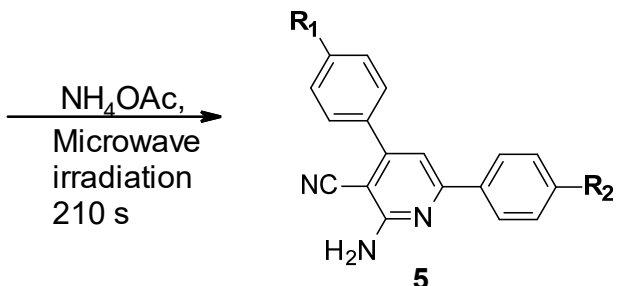

$\mathrm{R}_{1}, \mathrm{R}_{2}=\mathrm{CN}, \mathrm{OCH}_{3}, \mathrm{SCH}_{3}$

Scheme 2. Reaction route for microwave synthesis of 2-amino-4,6-diphenyl-pyridine-3carbonitrile derivatives.

Yield of microwave assisted synthesis of derivatives of 2-amino-4,6-diphenyl-pyridine-3carbonitriles obtained by path presented on scheme 2 are presented in the table 2 . As can be observed one pot synthesis assisted by microwave irradiation gives the same, or higher yields in apolar solvent, and even better results were observed in the presence TBAB.

Table 2. Yield of microwave assisted synthesis of 2-amino-4,6-diphenyl-pyridine-3carbonitrile conducted at traditional path.

\begin{tabular}{ccccc}
\hline Product & $\mathbf{R}_{1}$ & $\mathbf{R}_{2}$ & $\begin{array}{c}\text { Yield with } \\
\text { toluene }\end{array}$ & $\begin{array}{c}\text { Yield with toluene } \\
\text { and TBAB }\end{array}$ \\
\hline P0 & $\mathrm{H}$ & $\mathrm{H}$ & $35 \%$ & $33 \%$ \\
\hline $\mathbf{P 1}$ & $\mathrm{CN}$ & $\mathrm{H}$ & $30 \%$ & $32 \%$ \\
\hline $\mathbf{P 2}$ & $\mathrm{CN}$ & $\mathrm{OCH}_{3}$ & $42 \%$ & $50 \%$ \\
\hline P3 & $\mathrm{CN}$ & $\mathrm{SCH}_{3}$ & $57 \%$ & $58 \%$ \\
\hline $\mathbf{R} 1$ & $\mathrm{H}$ & $\mathrm{CN}$ & $32 \%$ & $30 \%$ \\
\hline $\mathbf{R 2}$ & $\mathrm{OCH}_{3}$ & $\mathrm{CN}$ & $36 \%$ & $43 \%$ \\
\hline $\mathbf{R 3}$ & $\mathrm{SCH}_{3}$ & $\mathrm{CN}$ & $27 \%$ & $30 \%$ \\
\hline $\mathbf{S 1}$ & $\mathrm{OCH}_{3}$ & $\mathrm{SCH}_{3}$ & $43 \%$ & $72 \%$ \\
\hline S2 & $\mathrm{SCH}_{3}$ & $\mathrm{OCH}_{3}$ & $45 \%$ & $86 \%$ \\
\hline
\end{tabular}


As can be observed at table 2, microwave synthesis shorten reaction time and enhance yields for almost all investigated compounds. At this conditions it was possible to synthesize sufficient amount of compounds in short time, without wasting materials and solvents.

To confirm structure of obtained derivatives ${ }^{1} \mathrm{H}$ NMR spectra were recorded at DMSO-D 6 solutions on Avance III HD $400 \mathrm{MHz}$ (Bruker) spectrometer. Collected data are presented in table 3 .

Table 3. Characterization of 2-amino-4,6-diphenyl-pyridine-3-carbonitriles derivatives by ${ }^{1} \mathrm{H}$ NMR spectra.

\begin{tabular}{|c|c|}
\hline Product & ${ }^{1}$ H NMR (400 MHz, DMSO-D 6 ) \\
\hline P0 & $\begin{array}{l}\delta 8.17-8.11(\mathrm{~m}, 2 \mathrm{H}), 7.72-7.66(\mathrm{~m}, 2 \mathrm{H}), 7.60-7.54(\mathrm{~m}, 3 \mathrm{H}), \\
7.52-7.47(\mathrm{~m}, 3 \mathrm{H}), 7.29(\mathrm{~s}, 1 \mathrm{H}), 7.03(\mathrm{~s}, 2 \mathrm{H}) .\end{array}$ \\
\hline P1 & $\begin{array}{l}\delta 8.17-8.11(\mathrm{~m}, 2 \mathrm{H}), 8.07-8.02(\mathrm{~m}, 2 \mathrm{H}), 7.91-7.86(\mathrm{~m}, 2 \mathrm{H}), \\
7.53-7.47(\mathrm{~m}, 3 \mathrm{H}), 7.33(\mathrm{~s}, 1 \mathrm{H}), 7.13(\mathrm{~s}, 2 \mathrm{H}) .\end{array}$ \\
\hline $\mathbf{P 2}$ & $\begin{array}{l}\delta 8.15-8.09(\mathrm{~m}, 2 \mathrm{H}), 8.07-8.01(\mathrm{~m}, 2 \mathrm{H}), 7.90-7.84(\mathrm{~m}, 2 \mathrm{H}), \\
7.27(\mathrm{~s}, 1 \mathrm{H}), 7.09-7.01(\mathrm{~m}, 4 \mathrm{H}), 3.82(\mathrm{~s}, 3 \mathrm{H}) .\end{array}$ \\
\hline P3 & $\begin{array}{l}\delta 8.13-8.07(\mathrm{~m}, 2 \mathrm{H}), 8.06-8.02(\mathrm{~m}, 2 \mathrm{H}), 7.90-7.85(\mathrm{~m}, 2 \mathrm{H}), \\
7.38-7.33(\mathrm{~m}, 2 \mathrm{H}), 7.31(\mathrm{~s}, 1 \mathrm{H}), 7.11(\mathrm{~s}, 2 \mathrm{H}), 2.53(\mathrm{~s}, 3 \mathrm{H}) .\end{array}$ \\
\hline $\mathbf{R 1}$ & $\begin{array}{l}\delta 8.36-8.28(\mathrm{~m}, 2 \mathrm{H}), 8.01-7.93(\mathrm{~m}, 2 \mathrm{H}), 7.74-7.65(\mathrm{~m}, 2 \mathrm{H}), \\
7.62-7.52(\mathrm{~m}, 3 \mathrm{H}), 7.41(\mathrm{~s}, 1 \mathrm{H}), 7.14(\mathrm{~s}, 2 \mathrm{H}) .\end{array}$ \\
\hline $\mathbf{R 2}$ & $\begin{array}{l}\delta 8.34-8.28(\mathrm{~m}, 2 \mathrm{H}), 8.00-7.93(\mathrm{~m}, 2 \mathrm{H}), 7.71-7.65(\mathrm{~m}, 2 \mathrm{H}), \\
7.38(\mathrm{~s}, 1 \mathrm{H}), 7.14-7.10(\mathrm{~m}, 2 \mathrm{H}), 7.08(\mathrm{~s}, 2 \mathrm{H}), 3.84(\mathrm{~s}, 3 \mathrm{H}) .\end{array}$ \\
\hline $\mathbf{R 3}$ & $\begin{array}{l}\delta 8.34-8.29(\mathrm{~m}, 2 \mathrm{H}), 8.00-7.94(\mathrm{~m}, 2 \mathrm{H}), 7.68-7.62(\mathrm{~m}, 2 \mathrm{H}), \\
7.46-7.40(\mathrm{~m}, 2 \mathrm{H}), 7.39(\mathrm{~s}, 1 \mathrm{H}), 7.13(\mathrm{~s}, 2 \mathrm{H}), 2.55(\mathrm{~s}, 3 \mathrm{H}) .\end{array}$ \\
\hline S1 & $\begin{array}{l}\delta 8.13-8.06(\mathrm{~m}, 2 \mathrm{H}), 7.69-7.62(\mathrm{~m}, 2 \mathrm{H}), 7.39-7.33(\mathrm{~m}, 2 \mathrm{H}), \\
7.24(\mathrm{~s}, 1 \mathrm{H}), 7.15-7.08(\mathrm{~m}, 2 \mathrm{H}), 6.93(\mathrm{~s}, 2 \mathrm{H}), 3.85(\mathrm{~s}, 3 \mathrm{H}) 2.54 \\
(\mathrm{~s}, 3 \mathrm{H}) .\end{array}$ \\
\hline S2 & $\begin{array}{l}\delta 8.14-8.09(\mathrm{~m}, 2 \mathrm{H}), 7.61-7.49(\mathrm{~m}, 2 \mathrm{H}), 7.09(\mathrm{~s}, 1 \mathrm{H}), 6.86- \\
6.80(\mathrm{~m}, 2 \mathrm{H}), 6.79-6.71(\mathrm{~m}, 2 \mathrm{H}), 6.66(\mathrm{~s}, 2 \mathrm{H}), 3.83(\mathrm{~s}, 3 \mathrm{H}) 2.56 \\
(\mathrm{~s}, 3 \mathrm{H}) .\end{array}$ \\
\hline
\end{tabular}

\section{Absorbtion and fluorescence characteristics}

Molecular absorption spectra of obtained fluorophores were recorded in acetonitrile, using the SilverNova spectrometer (StellarNet, Inc., USA) in combination with a broadband tungsten-deuterium UV-Vis light source (from StellarNet, Inc., USA), and a quartz cuvette with $1.0 \mathrm{~cm}$ optical path. Next, the absorbance data were converted into extinction coefficients, expressed in classical units $\left[\mathrm{dm}^{3} \cdot \mathrm{mol}^{-1} \cdot \mathrm{cm}^{-1}\right]$. 


\section{High Frequency Heating}

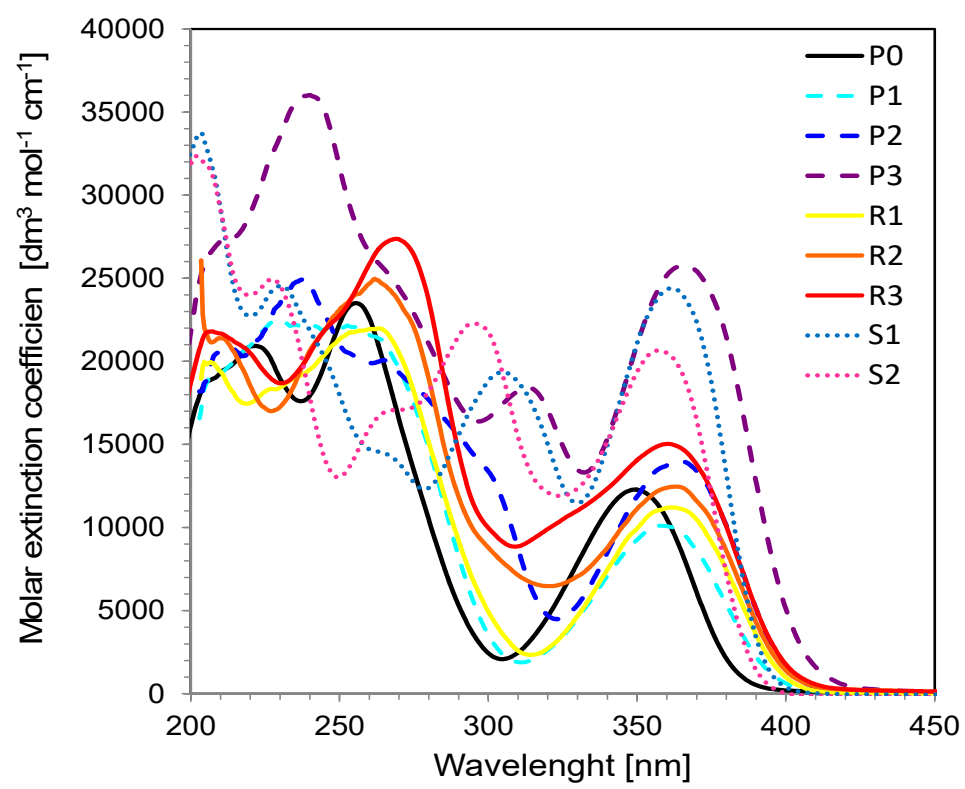

Figure 1. Molar extinction coefficient of investigated compounds investigated at acetonitrile solution.

The effect of substituents on absorption of the 2-amino-4,6-diphenyl-pyridine-3carbonitrile derivatives are clearly visible, significant differences in absorption and fluorescent spectra were observed especially between basis compound P0 and compound with best absorption characteristics $\mathrm{P} 3$ where batochromic shift of $20 \mathrm{~nm}$ is observed. Molar extinction coefficient of investigated compounds also distinguish obtained compounds depending on the structure. Best values are also assigned to compound P3, but also S1 and S2 reach very high value in comparison to others 2-amino-4,6-diphenyl-pyridine-3carbonitrile derivatives.

Fluorescence measurements were carried out using the same miniature spectrometer. The spectral characteristics of the sensors were measured in acetonitrile at room temperature $\left(22^{\circ} \mathrm{C}\right)$ using $1.0 \mathrm{~cm}$ thick quartz cells. As a source of excitation, the UV-LED $320 \mathrm{~nm}$ (UVTOP315-BL-TO39, Roithner Laser Technik GmbH, Austria) light was used. 


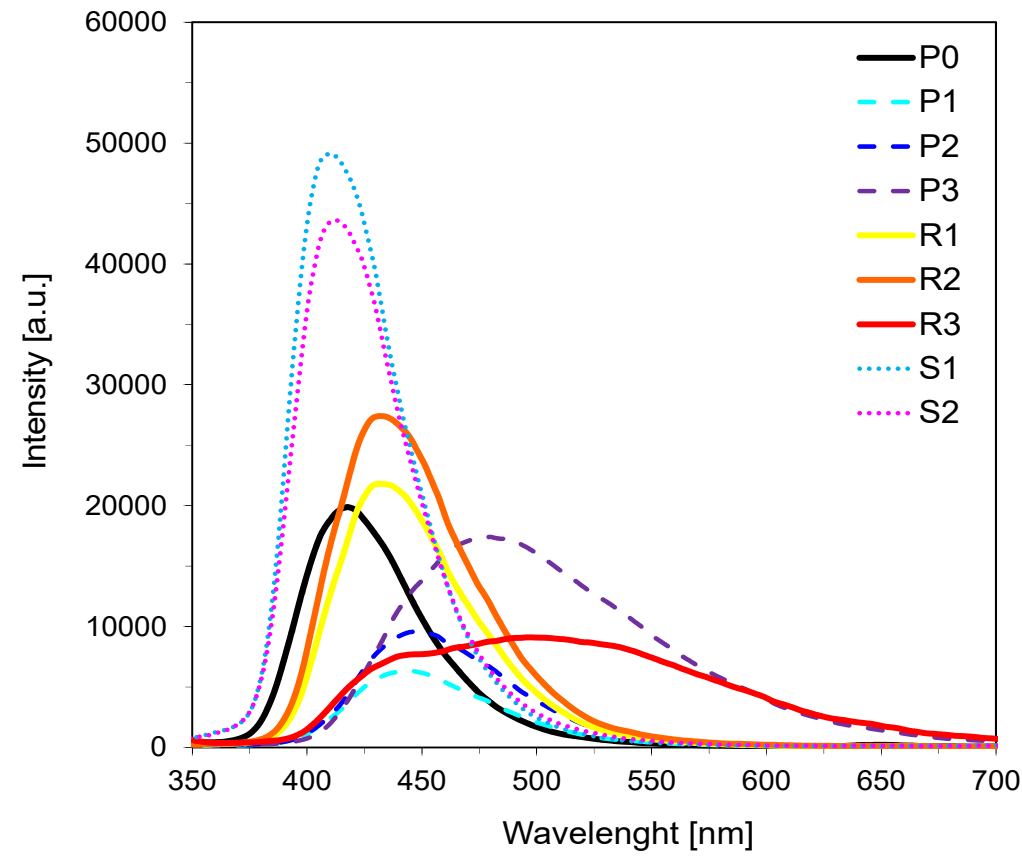

Figure 2. Fluorescence spectra of obtained compounds recorded at acetonitrile solution with excitation at 320nm with UV LED.

The introduction of two electron donor groups (methylthio and methoxy group) to the compound S1 and S2 resulting in significant increment of fluorescence intensity. Structure, where molecule contain both electron donor and electron acceptor moiety exhibit fluorescent spectra shifted to longer wavelength what can be useful in case of application as fluorescent molecular probes, where optical window must be found for every single application.

\section{Conclusion}

Traditional long time synthesis of 2-amino-4,6-diphenyl-pyridine-3-carbonitrile require higher volume of solvents used directly in synthesis, and also more complicated solvent-wasting purification.

Microwave synthesis is great convenience for synthesis of different derivatives as a base for screening tests. Thanks to extremely fast reactions with satisfying yields, and fact that reactions can be conducted with minimal necessary amounts of solvents and substratum a significant quantity of different compounds are prepared and analyzed in short period of time. Screening test of this group of fluorophores shown, that if fluorescence intensity is considered as most important factor for application of fluorescent probe, both substituents placed at external aromatic ring of obtained derivative should have electron donor characteristics. On the other hand, when longer wavelength of fluorescence is necessary both electron donor, and electron acceptor moieties should be simultaneously placed into fluorophore structure. 
Obtained compounds shows great spectral properties for application as fluorescent molecular probes into different fields of science, but their structure can be still refined by investigating other moieties and substituent placed at different places of fluorophore.

\section{References}

1. P. Gameiro, B. Castro, M. Rangel, A. M. G. Silva Eur. J. Org. Chem., 2012, 29, 5810-5817.

2. J. Ortyl, P. Fiedor, A. Chachaj-Brekiesz, M. Pilch, E. Hola, M. Galek, Sensors, 2019, 19.

3. F. Belhadja, Z. Kiboua, N. Cheikha,d, N. Choukchou-Brahama, D. Villeminb, Tetrahedron Letters, 2015, 56, 5999-6002.

4. R. Gupta, A. Jain, M. Jain, R. Joshi, Bull. Korean Chem. Soc, 2010, 3, 3180-3182.

5. S. Kambe, K. Saito, A. Sakurai, H. Midorikawa, Synthesis, 1980, 5, 366-368.

6. D. Khalili, Tetrahedron Letters, 2016, 57, 1721-1723.

7. S. Paul, R. Gupta, A. Loupyb, J. Chem. Research, 1998, 330-331.

8. J. Ortyl, K. Sawicz, R. Popielarz, J. Polym. Sci. A, 2010, 48, 4522-4528.

\section{Acknowledgement}

The authors are grateful to the Foundation for Polish Science (Warsaw, Poland) - Project REINTEGRATION (Contract No. REINTEGRATION/2016-1/4 - "Synthesis and photochemistry/photophysics studies of the intelligent luminescent molecular sensors for selective detection in biochemistry and chemistry") for financial support of the FPT research.

The authors also acknowledge the support of the PROM programme no. PPI/PRO/2018/1/00013/U/001 which is co-financed by the European Social Fund under the Knowledge Education Development Operational Programme. 